\title{
O TEXTO no Entre-Lugar. Processos de Nacionalização Literária
}

Francisco Salinas Portugal* salinas@udc.es

Resumo: Existem algumas obras literárias situadas numa posição ambígua no que à sua pertença diz respeito. São obras e autores que dificilmente formam parte duma literatura entendida como sistema, porém, numa tentativa que tem a ver com os processos identitários de construção nacional, a classe letrada de determinados momentos teve muito interesse em incorporá-las ao sistema literário respectivo. Para isso, serve-se de diferentes estratégias como são a construção de um romance histórico que permite criar a imagen pública do literato ou a utilização das personagens que se pretendem nacionalizar como personagens literárias à espera de que o leitor colabore na legitimação da (nova) tradição

Palavras-Chave: Nacionalização literaria, literaturas emergentes, sistema literário, legitimação da tradição literaria.

\section{ENTRE DOIS SISTEMAS}

Uma das questões teóricas que preocupam aqueles que se interessam pelas literaturas emergentes (emerging literature) é determinar os critérios que permitem estabelecer o corpus desse sistema.

Com efeito, enquanto as que poderíamos considerar literaturas normalizadas, quer dizer, literaturas cujo reconhecimento está implícito na sua mesma existência, a determinação do corpus não levanta problemas; ou, por outras palavras, para aqueles sistemas surgidos de processos sociais de

* Professor titular de Filologias Galega e Portuguesa. Universidade da Caruña (Galiza), Faculdade Filologia, Campus da Zapateira, 15071, A Coruña (Espanha). 
emergência política, a determinação do que é ou não essa literatura é tarefa, no mínimo, problemática.

Não se trata de sabermos a partir de que momento situamos o nascimento duma literatura e que motivos a singularizam, perspectiva que responderia a uma visão simplista e redutora do fenómeno literário e a uma instrumentalização com fins políticos, da mesma história literária. A essa procura do nascimento da literatura -neste caso, brasileira- refere-se Afrânio Coutinho nas páginas iniciais de uma obra de referência como $A$ Tradição Afortunada quando afirma:

Saber-se onde reside o divisor de águas entre a velha literatura e o novo rebento ultramarino. É o problema da origen da literatura brasileira, questão que se impôs a tôda a historiografia literária brasileira.

[...] Para ela [uma ala poderosa dos historiadores] a literatura brasileira é a literatura da era nacional, relegando a que surgiu durante a fase colonial para a literatura portuguesa, ou então, considerando-a, não como constituindo uma literatura, mas apenas manifestações literárias isoladas (COUTINHO, 1968, p. 9).

Ora bem, Antônio Cândido, desde uma posição radicalmente diferente, vai optar por um critério mais restritivo e, retomando a ideia da desnecessariedade de procurar o momento inicial da literatura, assume a empresa de definir quais os elementos que levam a que uma determinada produção artistica se constitua como um sistema.

Para este crítico e historiador literário, colocado nos antípodas do historiador baiano,

o problema da autonomia, da definição do momento e motivos que a distinguem [a literatura brasileira] da portuguesa, é algo superado, que não interessou especialmente aquí. Justificava-se no século passado, quando se tratou de reforçar por todos os modos o perfil da jovem pátria (CÂNDIDO, 1981, p. 28).

Quer dizer, apesar de a busca das origens, esse momento auroral da saída do caos à luz, ser um tema aliciante, o crítico brasileiro com cuja opinão não podemos senão concordar, centrar-se-á na concepção da literatura como sistema, quer dizer, daquelas

obras ligadas por denominadores comuns, [...] que são além das características internas, (língua, temas, imagens), certos elementos de naturaza social e psíquica [...] que se manifestam historicamente e fazem da literatura aspecto orgânico da civilização (CÂNDIDO, 1981, p. 23). 
Ora bem, quando um novo sistema emergente surge e se expressa na língua do sistema literário em cujo interior se formou, o início do novo sistema não é uma questão banal uma vez que a primeira característica que define uma literatura é a língua em que se exprime e o sistema de oposições que define uma literatura toma como base as línguas que os diferenciam ${ }^{1}$.

A literatura brasileira, de um lado e as literaturas dos países africanos de língua oficial portuguesa, de outro, na sua relação conflitual com a literatura portuguesa constituem um campo de operações em termos de história literária, certamente aliciante.

Com efeito, definir o termo ad quo dessas literaturas, apesar da afirmação de Antônio Cândido supracitada, pode ter interesse sempre que a procura do momento fundacional se inserir no estudo do campo literário que se está a formar e que é, em definitivo, o que permite definir uma literatura como sistema.

Portanto, há uma série de autores e/ou obras que pelo momento da sua emergência se situam numa posição intervalar entre os dois sistemas: um assente e consagrado e outro que começa a se constituir, quer dizer, obras e autores que se situam no espaço em branco, vazio, certamente ambíguo do entre-lugar.

Por sua vez, as histórias da literatura reflectem também, essa ambiguidade e a indefinição a este respeito é característica do discurso historiográfico.

Temos, portanto, as duas concepções do que é a literatura brasileira, o que é importante para entendermos o que é e como se situa (ou como dialoga) a obra e ou o autor de 1600 com obras e autores posteriores porque, em função da opção escolhida, os problemas que eventualmente pudessem aparecer, rapidamente desapareceriam. Aliás, as considerações que fizermos para a literatura brasileira têm aplicação, também, para as literaturas africanas de língua portuguesa.

BOCA DO INFERNO ENTRE DUAS PÁTRIAS LITERÁRIAS

Um autor que define muito bem esta dificuldade de adscrevê-lo a uma ou a outra literatura é Gregório de Matos (1623-1696). O hábil versejador, o sátiro irreverente, $\mathrm{o}$ iconoclasta blasfemo, o moralizador e o poeta obsceno é uma presença importante no Brasil seiscentista e as suas obras constituem manifestações literárias de interesse para a vida cultural do país.

Ora bem, só no Romantismo a figura de Gregório de Matos passa a formar parte do imaginário brasileiro quando, aliás, começa a tomar forma a ideia de um território-um Estado (o Estado-Nação), ideia essa que começa também a se integrar no interior do discurso da nova literatura. 
A nossa literatura é ramo da portuguesa; pode-se considerá-la independente desde Gregório de Matos ou só após Gonçalves Dias e José de Alencar, segundo a perspectiva adoptada (CÂNDINO, 1981, p. 28).

Temos, pois, o estado da questão: um poeta que já não é (portugués) mas também não é brasileiro, ou que é português e é também brasileiro.

Ora, as dúvidas que possam ter existido na contemporaneidade de Gregório de Matos (se é que existiram!), resolve o Romantismo acrescentando mais um nome ao novo Parnaso das letras brasileiras e se o Parnaso Brasileiro... de Januário da Cunha Barbosa inclui Gregório de Matos, o Florilégio de Vernhagen abre-se, precisamente com este autor. Também Araripe, recupera a figura deste polémico escritor baiano dado que nele vai encontrar o sentimento nativista, base da brasilidade. Isto obriga-o a fixar a atenção neste autor, por isso afirma

a contribuição [de Araripe Júnior] mais ponderável é no que atinge à valorização e compreensão da produção literária anterior à Independência, na qual situou a origem do sentimento nativista, elegendo Gregório de Matos como o símbolo do brasileirismo iniciante (COUTINHO, 1968, p. 129).

Entende-se, portanto, que este autor se mova numa certa indefinição dentro da crítica brasileirta e que Antônio Cândido resume muito bem quando o escolhe como exemplo dessa fase em que as "manifestações literárias" ainda não deram lugar à constituiução de um sistema

Embora tenha permanecido na tradição local da Bahia, ele [G. De Matos] não existiu literariamente (em perspectiva histórica) até o Romantismo, quando foi redescoberto, sobretudo graças a Vernhagen; e só depois de 1882 e da edição Vale Cabral pôde ser devidamenre avaliado. Antes disso não influiu, não contribuiu para formar o nosso sistema literário (CÂNDIDO, 1981, p. 24).

Portanto, podemos dizer que Gregório de Matos "começa" a existir na crítica literária brasileira com o Romantismo, movimento de tal modo seduzido pela vida extraordinária da personagem pública, que só parcelarmente editou a sua obra. Como indica Stegagno Picchio,

A questiondeggiamenti nel giudizio contribuiste profondamente lo statu degli studisu Gregorio de Matos, la cui vita avventurosa si sta solo ora riconstruendo in ogni sua tappa e le cui opere, che sappiamo correvano manoscritte nel 
Brasile coloniale, non hanno conosciuto pubblicazione sistematica sino alla fine dell'Ottocento (STEGAGNO, 1997, p. 54).

O que faz a estudiosa italiana com a "finezza" e exactidão que a carcterizam, é o processo de construção da própria imagen de Boca do Inferno e leva-nos à consideração de como autores e obras podem ser expulsos de um sistema ou incorporados a esse mesmo sistema sem problemas de maior. E isso vê-se no que às literaturas emergentes diz respeito e àqueles períodos da formação desses sistemas.

Ora bem, o que acabamos de ver põe de manifesto as duas concepções da história literária do Brasil (uma mais abrangente em que tudo é literatura brasileira - Afrânio Coutinho - e outra mais restritiva - Antônio Candido). Porém, um e outro não deixam de frisar o lugar problemático e ambíguo que esta figura representa; ambiguidade derivada desse entre-lugar em que a história literária colocou Gregório de Matos.

\section{A literatura das DescoberTAS E OS SISTEMAS literáRIOS aLTERNATIVOS}

Coincidindo com as viagens ultramarinas dos portugueses e as colonizações que se seguiram, o imenso territorio da África entrou no imaginário português. As viagens ultramarinas deram origem a toda uma produção literária que tem como pano de fundo, como décor onde se projectam as acções das personagens heroicas ou plebeias, que representam o friso social do Portugal de quinientos e seiscentos.

Ora, a literatura ultramarina cria um discurso mais ou menos literário de referencialidade africana passando este continente e as suas culturas, a integrarem um certo imaginário. Colocadas na perspectiva de fins do século XX ou inícios do século XXI, a literatura de viagens e da expansão constituem monumentos literários, históricos, etnográficos.... que formam parte também da história cultural dos novos países africanos antigas colónias portuguesas. Ora bem, que sejam importantes para a cultura desses países não significa, necesariamente, que formem parte das respectivas literaturas; como indica Manuel Ferreira

É evidente que esta literatura, nascida de uma experiência planetária, numa época em que o mundo cristão reconhecia o direito à dominação, à depredação e até à barbarie [...] nada tem a ver com a literatura africana de expressão portuguesa. Este registo destina-se apenas ou, sobretudo, a retermos factos longinquamente relacionados com o quadro cultural e político que, séculos depois, havia de surgir (FERREIRA, 1986, p. 12). 
Portanto, esta literatura portuguesa da expansão, sendo interesante para a história cultural dos países africanos, não forma parte das literaturas africanas, constituindo manifestações literárias que isoladamente não formam um sistema.

É neste contexto que devemos, também, situar a História Geral das Guerras Angolanas de António de Oliveira de Cadornega, não só pelo texto em si do relato das guerras angolanas propriamente dito e tudo o que está à sua volta, como por incluir algum texto como o poema do capitão António Dias Macedo.

Ora bem, a obra de Cadornega, "cidadão de Vila Viçosa" publicada em 1680 representa um importante monumento literário que a Angola diz respeito sem que, do nosso ponto de vista, se possa afirmar que nela resida qualquer forma de incipiência literária.

Ao contrário do que aconteceu com Gregório de Matos, contemporâneo de Cadornega e que, como ele, também viveu em África, Cadornega foi sempre considerado um autor portugués da expansão ultramarina.

Porém, quando do século XX, nomeadamente a partir do projecto fundacional da Mensagem e do Vamos Descubrir Angola!, a intelectualidade angolana começa a se interesar pelo seu passado colonial, Cadornega é "descoberto", iniciando-se assim um processo de recuperação e de nacionalização muito interesante.

Com efeito, foi Mário António que em texto publicado na revista Ultramar (logo incluído em Reler África) fez as seguintes considerações que nos parecem de extraordinário valor. Diz o poeta e crítico angolano:

Nestas ordens de ideias e porque é sobre textos que toda a crítica, como toda a história literária, tem de se fazer, começarei por me servir da seiscentista História Geral das Guerras Angolanas, de António de Oliveira de Cadornega [...]. E é, quando a leio, muitas vezes o seu interesse como fonte de informação histórica desaparece ante o prazer da sua linguagem rica e colorida, que, se por um lado se aproxima da dos autores metropolitanos coevos [...], pelo outro, se diferencia pelo matiz africano nela tão harmoniosa e naturalmente presente. Creio que a expressão literária de Cadornega [...] documenta uma realidade cultural simbiótica, que é aquela que, até hoje, e, para além e a pesar de todos os polemismos, tem sido o único suporte válido daquilo a que se pode chamar a Literatura Angolana. Não estarei longe da verdade se afirmar que poucos escritoires de Angola, até hoje, usaram de uma linguagem tão rica de colorido angolano como a do autor da História Geral da Guerras Angolanas (OLIVEIRA, 1990, p. 481). 
Vale a pena fazer esta citação tão longa porque uma reivindicação tão clara de Cadornega para a literatura angolana não se vai encontrar em tempos posteriores e, apesar da reivindicação de Mário António e de outros críticos posteriores, Cadornega não entrou nuna história da literatura angolana.

$\mathrm{Na}$ mesma linha, outro crítico africanista como Francisco Soares, retoma e continua a ideia exposta por Mário António:

O já citado ensaísta, Mário António Fernándes de Oliveira, foi um dos que fundadamente falou das primeiras ilustrações significativas que temos do processo de formação de uma literatura local, periodizando-as no século XVII: de um lado um cronista como António de Oliveira Cadornega, autor da História Geral das Guerras Angolanas [...] do outro, 'filhos do país' letrados (SOARES, Francisco, 2001, p. 25).

Na sequência desta argumentação, o crítico africanista esforça-se por tornar patente uma continuidade literária que passaria pelos festejos (concurso poético incluído) que se celebram na cidade de Luanda com motivo da beatificação do futuro S. Francisco Xavier. Mesmo assim, Francisco Soares vai chamar a atenção para uma série de famílias ilustradas que, ao longo do século XVII e XVIII, conformariam a base da continuidade literária. Estas propostas, a serem aceites, obrigariam a uma reformulação da periodização da literatura angolana.

Há uma linha da história literária de Angola que se remontaria à obra de Cadornega ${ }^{2}$. Porém essa perspectiva não vingou nos estudos africanistas e parece mais oportuno situarmos o inicío da literatura por volta da instalação da imprensa, no século XIX, porque aí se dão os elementos que configuram o campo literário e, em consequência, por tanto, podermos considerar a literatura como um sistema.

\section{A FUNÇÃO IDENTITÁRIA DA HISTÓRIA DA LITERATURA}

Para entendermos essa posição ambígua no que à adscrição literária diz respeito, destas obras que têm como elemento definidor a sua própria intervalaridade, temos que remontar-nos à elaboração das histórias literárias no século XIX, cujos pressupostos, curiosamente, em boa medida se mantêm no século XX.

Com efeito, situando as histórias da literatura no contexto das formulações nacionalistas do Romantismo, podemos afirmar que "a história literária oitocentista centra-se na 'nação' [e que] num espaço discursivo plurímodo, as verdadeiras fronteiras que estabelece são as fronteiras 'nacionais"' (CUNHA, 
2002: 131). Isto é o que explica que para Teófilo Braga - e tomamos o exemplo de Teófilo Braga enquanto modelo de História literária de Portugal tendo em conta, aliás, que a formulação brasileira é devedora do modelo europeu -, literatura e identidade nacional se tornem indissociáveis, "estímulo e apoio à idependência nacional". Teófilo é, assim, junto com Herculano e Garrett, pioneiro "nesta articulação entre literatura e sociedade nacional (CUNHA, 2002, p. 136).

Criar um passado é pois um objectivo essencial para os formuladores da nação. E criar esse passado implica também criar a respectiva tradição, sendo só aí que a nação se reconhece. E na narrativa nacional insere-se, também, e pour cause, a tradição da sua literatura. É por isso que Juan Thompson, no longínquo 1834, formula toda uma teorização a respeito da sua concepção de tradição literária e que González Stephan resume da seguinte maneira:

1. Uma literatura no se define a partir de la existencia empírica de las obras. 2. Una literatura es el resultado de una actividad teórica que las estudia, las ponga en relación, establezca los conjuntos literarios, diseñe el sistema en el cual se insertan y cobran sentido.

3. Una tradición literaria $[\ldots]$ es una construcción reflexiva., es una abstracción $[\ldots]$.

4. Para que exista una literatura que sea nacional, debe haber con antelación una serie de niveles diferenciables por sus cualidades: una realidad nacional orgánicamente articulada y una crítica e historias literarias. La literatura de un país es el resultado de la intelección que se ha hecho sobre ellas (GONZÁLEZ, 2002, p 198-9).

Como podemos ver, o prestigio de uma história literária mede-se não só pela eventual qualidade das obras que a integram, como também pela "antiguidade" que o corpo social lhe reconhece. Com efeito, a procura dessas origens está intimimente ligada à construção nacionalista

La invención de los orígenes es, pues, un acto de afirmación, de ruptura con otras tradiciones y, sobre todo, de autorización de la tradición alternativa que aspira a reemplazar la tradición vigente (LLORENS, 1998, p. 94-5).

E nessa invenção das origens está, também, a invenção do passado literário reescrevendo, dessa maneira, uma (nova) tradição literária. Assim, os letrados nacionalistas, entre os quais se incluem os escritores -muitos deles figuras preeminentes dos movimentos nacionalistas - procuram a filiação com esse pasado longínquo e exemplar. 
Nem a língua em que os textos são escritos, nem a origem do autor, nem a temática que se desenvolve nos textos são critérios suficientes para qualificar uma literatura ou um autor como pertencente a esta ou aquela literatura. Será, do nosso ponto de vista, a concepção da literatura como sistema a que nos permitirá falar desta ou de outra literatura.

Por isso, nessa perspectiva, a Carta de Vaz de Caminha ou os discursos de Anchieta não são literatura brasileira por muito que sejam obras essenciais para a cultura brasileira e até para a fomação da nacionalidade.

Do mesmo modo, a obra de Cadornega não é literatura angolana por muito importante que seja para o conhecimento do passado de Angola a obra do cronista do século XVII.

O importante, do nosso ponto de vista, é a inexistência de um campo literário onde circulem as obras indicadas. Não é suficiente com que exista um grupo de escritores, nem um grupo de receptores (leitores) ou ainda uma temática identificável para podermos falar de um sistema por muito que todos eles sejam necessarios e todos eles se interrelacionem formando um conjunto que configura o sistema como nos explica Fernando Cristóvão:

Onde há uma conciência colectiva de integração no conjunto, um património reconhecido como próprio, uma tradição que é, simultáneamente, repositório e elemento vivificador de identidade. Onde o escritor possa imaginar o seu público, e onde os leitores saibam distinguir os "seus" dos "outros" (CRISTÓVÃO, 1981, p. 373-4).

O que o professor Cristóvão está a sublimar é o sentimento de pertença como elemento identificador de um sistema coeso.

Ora bem, se trasladarmos esta ideia - que no fundo não é senão a centralidade do conceito de campo literário - às literaturas brasileira e africanas de língua portuguesa, situaremos o início da literatura brasileira no seúlo XVIII:

O momento decisivo em que as manifestções literárias vão adquirir, no Brasil, características orgânicas de um sistema, é marcado por três correntes principais de gosto e pensamento: $\mathrm{O}$ Neoclassicismo, a Ilustração, o Arcadismo (CÂNDIDO, 1981, p. 43).

Sobre esta definição, podemos passar a considerar como literatura brasileira o período indicado e, portanto, Gregório de Matos não pertenceria 
a esta literatura ${ }^{3}$ na concepção já indicada de Antônio Cândido da literatura como sistema. E isso, a pesar de todo o esforço que se faz desde o Romantismo por integrar (nacionalizar) o escritor baiano na tradição literária do Brasil e, portanto, no sistema literário brasileiro.

No que diz respeito a Angola, a situação parece mais clara. Cremos que a introdução da imprensda na colónia e as publicação do respectivo Boletim Oficial do Governo Geral da Província de Angola (1845) pode ser considerada uma data consensual para o início da literatura angolana ${ }^{4}$ porque o Boletim lança as bases da infraestrutura necessária para iniciar o processo de constituição do campo literário que, de facto, só se irá conseguir com a geração da Mensagem. Carlos Ervedosa, que integrou ele própio este movimento, reflecte sobre a Mensagem nos seguintes termos:

Movimento de poetas, contistas e ensaistas, foi essencialmente através da poesia que aquele grupo de jovens, no dealbar da segunda metade do século vinte, se impôs e logrou virar uma página da história da literatura angolana. Pouco tempo de actividade lhes foi permitido. Publicaram-se apenas dois números da revista, realizou-se um concurso literário e publicou-se uma pequena antologia (ERVEDOSA, 1979, p. 125).

Apesar desses magros resultados, estes são, parece-nos, de enorme importância em termos de constituição do campo literário (estabelecimento do cânone, mercado dos produtos culturais, constituição do grupo leitor...).nesta consideração, portanto, Cadornega ficaria fora da tradição literária de Angola.

\section{ESTRATÉGIAS DE NACIONALIZAÇ̃̃O}

Quer no Romantismo brasileiro, quer nos períodos de formação dos sistemas africanos, observamos que se dá uma tentativa de alargar o período da história literária dos respectivos países.

Com efeito, o Romantismo brasileiro, como período-chave na criação da literatura brasileira e chave também na formulação da nação, tentará, num movimento geral a todos os contextos de emergência política, apresentar um passado literário brilhante e com marcas de "diferença" (brasilidade) que permitam ao leitor reconhecer um passado que alicerça um presente também brilhante e um futuro promissor.

No caso de Angola, reproduzimos, em linhas gerais, um esquema similar. O grupo letrado da geração da Mensagem, que formula não só uma nova literatura como também um esquema político tendente à independência 
(embora, obviamente, o termo nem apareça no discurso da intelectualidade) procurará também monstrar um passado político e literário condizente com o futuro que almejam para a sua sociedade.

Quer num caso, quer no outro, as tradições literárias respectivas vêem-se acrescentadas com autores como Gregório de Matos num caso ou Cadornega noutro. Se no primeiro caso, dado o tempo em que isso está sendo realizado, o prestígio das vozes críticas que têm apoiado essa ideia (de Araripe a Afrânio Coutinho), Gregório de Matos pode ser estudado na literatura brasileira, quer dizer, a recepção do autor tem "nacionalizado" o escritor (embora não na sua totalidade como já tivemos ocasião de indicar neste artigo). Já com Cadornega a situação é levemente diferente, também por causa do tempo transcorrido entre as primeiras formulações da história literária angolana e a actualidade, assim como pela ausência de consenso crítico a este respeito (a linha crítica de incluir Cadornega na história da literatura angolana tem apenas a referência de Mário António no passado recente e de Francisco Soares na actualidade) parecem não aceitar como indiscutível o alargamento da tradição literária de Angola até o século XVII.

Ora bem, no processo de leitura há dois exemplos, como estratégias de nacionalização, que parecem interessantes ou pelo menos susceptíveis de serem discutidas

No caso de Gregório de Matos, uma escritora actual, Ana Miranda publica em 1989 um romance histórico, Boca do Inferno, onde é literaturizada a figura do polémico escritor baiano, fazendo com que o leitor, através da empatia com a figura protagonista, possa passar a interpretar Gregório de Matos como um escritor "seu". Isto quer dizer que no processo de recepção existem mecanismos da ordem da afectividade (não objectiváveis portanto) que podem levar o leitor a essa apropriação irracional de determinadas figuras literárias. Talvêz se trate desse "sentimento íntimo" de que falava Machado de Assis em "Instinto de nacionalidade" de que participam autor e leitor -usamos o termo não na definição exacta que dá Machado, mas pelo que tem de irracional na sua proposta-. Ora bem, isto não quer dizer que todo o personagem histórico ficcionalizado se tenha que converter em escritor próprio, mas pensamos que pode ser uma estratégia que reforce o sentido de pertença do autor, nomeadamente em contextos e situações de instabilidade. Já indicámos que a inclusão de Gregório de Matos na literatura brasileira não é consensual e, portanto, o que faz Ana Miranda, pela via da ficção histórica, é tomar uma opção, desde a criação literária, a favor duma determinada visão da literatura.

A reescrita da história que todo o romance histórico implica, leva a autora a apresentar um escritor "mais" brasileiro do que talvez a realidade 
assinala. Como, exemplo, na parte final do romance onde se dá conta do destino das personagens, escreve Ana Miranda (1990, p. 296):

Algum tempo depois, Gregório, de Matos saiu do presídio de Lioneira e foi degredado para Angola, Numa caravela onde ia, também, a tropa de cavalos de el-rei de Benguela. Gregório de Matos despediu-se, para sempre, da cidade que tanto amava e odiava. Adeus praia, adeus cidade, adeus povo, adeus Bahia, adeus canalha infernal.

No que diz respeito a Cadornega, Pepetela vai utilizar de duas maneiras o historiador seiscentista, também num romance histórico, A Gloriosa Familia.O Tempo dos Flamengos. ${ }^{5}$ Por um lado, Cadornega forma parte dos critérios de veredição da obra e, por outro, converte-se numa personagem secundária do romance.

Com efeito, seguindo uma estratégia habitual no romance histórico (e mais no romance histórico pós-moderno), a obra abre-se com um "prólogo" que é um excerto da História de Cadornega, tipograficamente diferente do corpo do romance. Talvez a aparição de Cadornega e outros autores que aparecem no início de diferentes capítulos, tem como finalidade apresentar o discurso histórico que dialoga e se complementa com o novo "discurso histórico" que o romance actualiza.

Porém, o que nos parece mais interesante do ponto de vista da "nacionalização" (a sua inclusão na literatura angolana) é o facto de o autor ter recorrido à utilização da personagem Cadornega dentro da própria diegese. Com efeito, sem se tratar de uma personagem importante no desenvolvimento da obra, a inclusão da personagem de Cadornega, embora não tenha grande importância para o desenvolvimento da obra, cria no leitor a certeza de que este é mais um autor angolano. Veja-se, de entre muitas, a seguinte citação:

Nascido e criado em Vila Viçosa, importante praça do Alentejo, em Portugal, Cadornega viera com um irmão no mesmo barco do governador Pedro Cesar de Menezes. Me recordava dele, nos tempos da fuga de Luanda, não só por fazer olhos sofredores quando divisava Matilde, mas por andar com papéis onde tomava notas constantemente (PEPETELA, 1998, p 260-261).

As referências a Cadornega como homem de letras são constantes em toda a obra "Gostei de ouvir o alferes Cadornega, homem de letras e de pensamento, reconhecer o mérito do meu rei, sendo o inimigo mais odiado" (PEPETELA, 1998, p 262). 
Porém, a situação mais interesante, narrativamente falando, da apropriação da História de Cadornega encontramo-la num momento onde o narrador nos informa:

Soube uns tempos depois, Cadornega falhou no dilema [...] Cadornega até conhecia a profecia, aparecendo como da autoria de um jesuita, afinal seu mais ditoso rival. "Lembrava-lhe uma como profecia predita por um religioso... [segue-se uma citação da História Geral, assim recolhida com a sua referência completa] (PEPETELA, 1998, p. 269).

\section{Considerações Finals}

É uma constante em todas as literaturas emergentes procurar um passado literário esplendoroso e, em todo o caso, rico em termos qualitativos e quantitativos. É verdade que, como em todos os sistemas literários, a construção de uma tradição é uma tarefa inadiável para todos esses sistemas porque é nela que todos se reconhecem e é em relação a ela que todos avaliamos progressos e a acumulação de capital simbólico que constitui a tradição literária.

No caso que analisamos aquí, duas obras contemporâneas (brasileira e angolana) são utilizadas para alargar a tradição literária dos respectivos países. Num caso, para corroborar uma opção de pertença (Gregório de Matos), noutro, para modificar as balizas cronológicas do sistema (Cadornega). O que com ambos os autores se pretende é fixar os contornos duma literatura nacional para reconhecer, com Fernando Cristóvão, que "são nacionais todos os autores e obras que circulam num determinado sistema comunicativo cultural-literário nacional, usadas e entendidas como fazendo parte dele" (CRISTÓVÃO, 1981, p 376-7).

Integra-se Gregório de Matos no sistema literário brasileiro? É Cadornega um dos primeiros representantes da literatura angolana?

Eis duas perguntas cuja resposta as histórias da literatura por enquanto não conseguiram dar... e, talvez nem seja preciso.

\section{The Text In The Between Place: Processes Of Literary Nationalization}

ABstract: There exist literary works placed in an ambiguous position for what it refers to his belonging to one or another system. They are works and authors who hardly form a part of a literature understood as a system, nevertheless in an attempt that it has to see with the identitarios processes of national construction, the learned class was interested in incorporating them into the respective system. 
For that it makes use of diifferent strategies as the construction of a historical novel that allows to create the public image of the writer or the utilization of characters that try to be nationalized like literary characters waiting for the collaboration of the reader for his legitimization.

KEYWORDS: Literary nationalization; emerging literature; literary system; legitimization of the literary tradition

NOTAS

1 Não vamos centrar o debate post-Herder certamente aliciante para as literaturas que surgem entre os séculos XVIII e XIX, como o caso da brasileira, porque o que o pensador alemão acretitou ter encontrado como princípio identificador do Volksgeist ou espírito de uma nação, a língua, "no coincide por fuerza con las circunstancias y las intenciones que sostienen el surgimiento de una institución literaria nacional" (GUILLÉN, 2007, p. 301). Apesar de as investigações recentes sobre a constituição dos sistemas literários não tenha priorizado o elemento linguístico, é verdade que a língua continua a ocupar uma parte central nesse debate.

2 Além de Mário António e Francisco Soares, também Pepetela tem reconhecido essa origen em Gazeta de poesia do Mundo de Língua Portuguesa, no 1-2, segundo recolhe F. Soares (ob. cit., p. 25-nota) mas que não tivemos ocasião de consultar.

3 Antônio Cândido aventura mesmo uma data de "nascimento" da literatura brasileira: "Já que é preciso um começo, tomei como ponto de partida as Academias dos Seletos e dos Renacidos e os primeiros trabalhos de Cláudio Manuel da Costa, Arredondo, para facilitar, a data de 1750, na verdade puramente convencional" (Cândido, 1981, p. 24).

4 Nós próprios (SALINAS, 1999) temos insistido nessa importância na periodização da literatura angolana.

5 Uma análise mais demorada deste romance, foi feita por nós em "A ficcionalizaçao da história e o romance histórico: A Gloriosa Família de Pepetela". Mar Além (revista de cultura e literatura dos paises africanos de língua oficial portuguesa). Lisboa, Volume 1, 2002, p 55-62, 2002.

\section{REFERÊNCIAS}

CÂNDIDO, Antônio. Formação da Literatura Brasileira. Belo Horizonte: Itatiaia, vol. I, 1981.

COUTINHO, Afrânio. A Tradição Afortunada. Rio de Janeiro: Liv. José Olympio Editora, 1968. 
CRISTÓVÃO, Fernando. A literatura como sisterma nacional. Brotéria, Braga, vol. 112, n 4, Abril, p 363-383, 1981.

ERVEDOSA, Carlos. Roteiro da Literatura Angolana. Lisboa: Edições 70/2a ed., 1979. FERREIRA, Manuel. Literaturas Africanas de Expressão Portuguesa. Lisboa: ICALPBiblioteca Breve, vol I, 1986.

GONZÁLEZ-STEPHAN, Beatriz. Fundaciones: canon, historia y cultura nacional. Madrid/ Frankfurt: Iberoamericana/ Vervuet, 2002.

GUILLÉN, Claudio. Múltiples moradas. Ensayo de literatura comparada. Barcelona: Tusquets editores, 2007.

LLORÉNS, Irma. Nacionalismo y literatura. Constitución e institucionalización de la 'Repúblicas de las letras cubana'. Lleida: Universitat de Lleida, 1998.

MIRANDA, Ana. Boca do Inferno. Lisboa: Publicações Dom Quixote, 1990

OLIVEIRA, Mário António F. Duas condições humanas como suportes da literatura angolana. Reler África. Coimbra: Instituto de Antropologia-Universidade de Coimbra, p 481-487, 1990.

PEPETELA. A Gloriosa Familia. O Tempo dos Flamengos. Lisboa: Publicações Dom Quixote, 1998.

SALINAS Portugal, Francisco. Entre Próspero e Caliban. Literaturas Africanas de Língua Portuguesa. Santiago de Compostela: Laiovento, 1999.

SOARES, Francisco. Notícia da Literatura Angolana. Lisboa: Imprensa NacionalCasa da Moeda, 2001.

STEGAGNO PICCHIIO, Luciana. Storia della letteratura brasiliana. Torino: Einaudi editore, 1997. 